\title{
Functionally graded Ni-Ti microstructures synthesised in process by direct laser metal deposition
}

\author{
T. E. Abioye • P. K. Farayibi • P. Kinnel • A. T. Clare
}

Received: 17 July 2014 / Accepted: 4 February 2015 / Published online: 19 February 2015

(C) The Author(s) 2015. This article is published with open access at Springerlink.com

\begin{abstract}
The fabrication of biomedical devices using $\mathrm{Ni}$-Ti compositions is limited to conventional techniques and the use of near equiatomic pre-alloyed $\mathrm{Ni}$ and $\mathrm{Ti}$ powders. In this study, functionally graded walls and cylinder built by concurrent feeding of $\mathrm{Ni}$ powder and commercially pure (CP) Ti wire using direct laser metal deposition technique are presented. The built structures consist of CP Ti wire-deposited layers and Ni-Ti layers of varying $\mathrm{Ni}$ composition. The microstructures of the built Ni-Ti structures including phase identification, phase compositions and area fractions of the phases present at various processing parameters were determined using a combination of scanning electron microscopy/ energy dispersive X-ray spectroscopy, X-ray diffractometry and image processing software. Vickers microhardness test was conducted on the deposited structures. It was found that the Ni-Ti layers comprise of NiTi and $\mathrm{NiTi}_{2}$ phases. The area fraction of the NiTi phase increases, whereas $\mathrm{NiTi}_{2}$ decreases with increasing the $\mathrm{Ni}$ powder feed rate. Ni-Ti layers with higher area fractions of $\mathrm{NiTi}_{2}$ phase are found to be harder with a maximum of $513 \mathrm{HV}_{0.3}$ found in this study. The micro-hardness of $\mathrm{Ni}$-Ti layers is, by at least a factor of 1.5 , higher than the CP Ti wire laser-deposited layers.
\end{abstract}

Keywords Ni-Ti · Direct laser metal deposition . Micro-hardness $\cdot$ Functionally graded component . Microstructure

T. E. Abioye $\cdot$ P. K. Farayibi $\cdot$ P. Kinnel $\cdot$ A. T. Clare $(\triangle)$ Department of Mechanical, Materials and Manufacturing Engineering, University of Nottingham, Nottingham, UK e-mail: adam.clare@nottingham.ac.uk

\section{Introduction}

$\mathrm{Ni}$-Ti alloys have found applications in many areas of engineering ranging from aerospace to biomedical [1]. This is due to their unique properties such as superelasticity, biocompatibility, shape memory effect and excellent corrosion resistance which have made them a material of choice for the manufacture of vascular stents and other medical devices used for bone and tissue replacement in the human body [2,3]. Also, these unique properties combined with a high strength to weight ratio and high toughness make Ni-Ti a commonly used material for energy dissipation in landing gear and other related aerospace structural subsystems [4]. The manufacturing techniques for making Ni-Ti structures include conventional sintering, self-propagating high-temperature synthesis (SHS), sintering at elevated pressure via a hot isostatic pressing (HIP), spark plasma sintering (SPS) and metal injection moulding (MIM). Compared to additive manufacturing (AM) techniques, such as selective laser melting (SLM) and direct laser metal deposition (DLMD), the aforementioned techniques are slower and limited in design freedom. Through AM, components with complex geometries without a use of cutting tools or fixtures can easily be built [1]. Also, the microstructure, hence, the properties of the components built using AM techniques can be tailored to the required design intent by controlling the processing parameters [5].

Near equiatomic pre-alloyed powders are predominantly used for fabricating Ni-Ti structures. The 50:50 atomic ratio of $\mathrm{Ni}$ and Ti powders is a key to the shape memory effect of the alloy. However, past investigations have revealed that the corrosion resistance of the $\mathrm{Ni}$-Ti components is enhanced by the formation of oxide of $\mathrm{Ti}$ on the surface; however, the release of $\mathrm{Ni}^{+}$ion lowers the corrosion performance [6]. Also, it has been identified that high $\mathrm{Ni}$ content of Ni-Ti alloys has been a concern to clinicians due to the allergic and toxic nature of $\mathrm{Ni}$ in the human body [2]. Accordingly, a large number of 


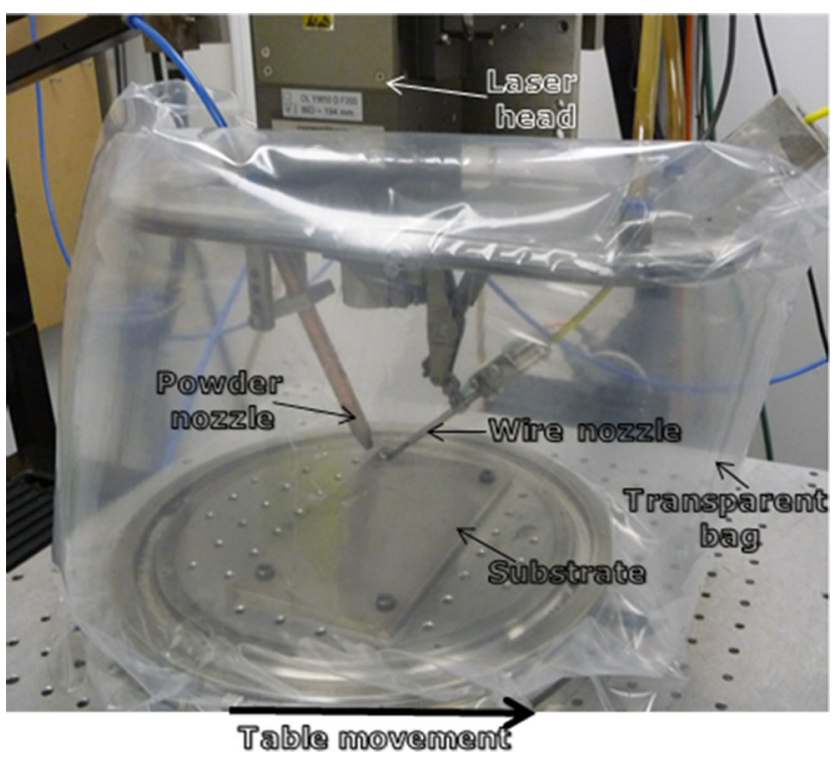

Fig. 1 A picture of the experimental set-up

surface treatments have been proposed and implemented in order to reduce the content of nickel in the surface oxide film [7]. These include ion implantation, mechanical polishing, chemical etching and selective oxidation. The result is the depletion of $\mathrm{Ni}$ on the surface of $\mathrm{Ni}$-Ti components producing improved corrosion resistance. $\mathrm{Ng}$ et al. [8] studied the corrosion performance of $\mathrm{Ni}$-Ti laser surface alloyed with $\mathrm{Nb}$ or $\mathrm{Co}$. It was found that the corrosion as well as the hardness of the surface increased as the $\mathrm{Ni}$ content decreased. However, the load-bearing applications of the Ni-Ti component will suffer because of the alteration in the $\mathrm{Ni}$ content.

It is therefore necessary to develop a manufacturing method which allows for these properties to be tuned in a single component. A possible approach is by making functionally graded components such that the Ni content is varied at various positions of the built structures. This is best achieved by independent feeding of $\mathrm{Ni}$ and $\mathrm{Ti}$ while building the components. Unlike SLM, DLMD allows for (1) independent feeding of two different powders and (2) concurrent use of wire and powder as the material feedstocks during laser processing.
The use of wire gives better process economy by reducing material wastage hence process costs [9].

In this study, functionally graded Ni-Ti structures were fabricated by concurrently feeding $\mathrm{Ti}$ wire and Ni powder into a laser melt pool. The Ni content was controlled by varying the powder feed rate (PFR) at different cladding positions according to the design intent. Also, the microstructure and microhardness of the Ni-Ti laser-deposited layers as a function of the Ni content were investigated.

\section{Experimental procedure}

\subsection{Materials and laser processing}

Figure 1 shows a picture of the experimental set-up for the concurrent wire and powder laser deposition system utilised in this study. The depositions were performed using a 2-kW ytterbium-doped fibre laser (IPG Photonics) operating at $1070 \mathrm{~nm}$ wavelength. The beam was focused to a small round spot of diameter $3.1 \mathrm{~mm}$ at $20 \mathrm{~mm}$ beyond the focus, giving a 212-mm working distance with a Gaussian energy distribution.

Commercially pure (CP) Ti wire of $1.2 \mathrm{~mm}$ diameter supplied by VBC Group (Loughborough, UK) was 'front fed' (ahead of the laser beam) at an angle of $42^{\circ} \pm 1$ to the horizontal so as to aim the wire tip at the centre of the meltpool. Pure Ni powder $(40-240 \mu \mathrm{m}$; mean size $=135 \mu \mathrm{m})$ was back fed into the meltpool through a Praxair (model 1264) powder feeder. The powder nozzle of diameter $2 \mathrm{~mm}$ at the orifice was directed to the centre of the laser spot initially created on the substrate. The nozzle was oriented at $67^{\circ}$ to the horizontal so as to improve the powder deposition rate. The $\mathrm{Ni}$ powder is nearly spherical in shape, as shown in Fig. 2a. Ti$6 \mathrm{Al}-4 \mathrm{~V}$ plate of dimension $180 \mathrm{~mm} \times 80 \mathrm{~mm} \times 6 \mathrm{~mm}$ was used as the substrate material. The composition of the substrate is given in Table 1.

The protrusion distance from the powder and wire nozzles to the substrate (Ti-6Al-4V plate) was kept at $10 \mathrm{~mm}$ so as to prevent melting of the nozzles by the laser beam. All
Fig. 2 a Secondary electron SEM image of the Ni powder utilised for this work and $\mathbf{b}$ a schematic image showing the unidirectional motion of laser beam during the walls deposition

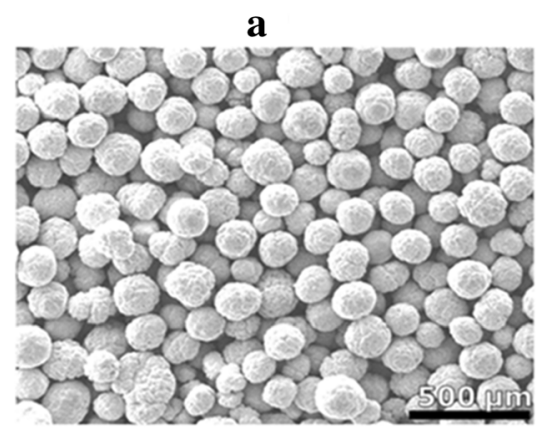

b

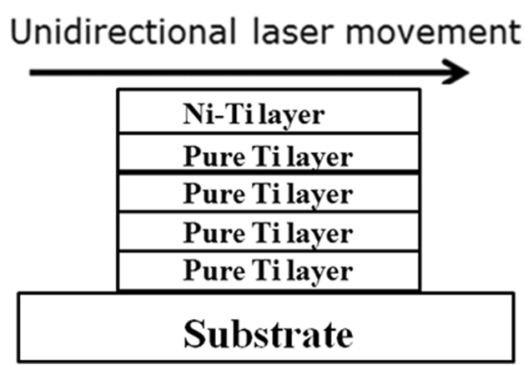


Table 1 Composition of Ti-6Al-

$4 \mathrm{~V}$ (grade 5) in wt $\%$ [10]

\begin{tabular}{lllllllll}
\hline Element & $\mathrm{C}$ & $\mathrm{Fe}$ & $\mathrm{N}_{2}$ & $\mathrm{O}_{2}$ & $\mathrm{Al}$ & $\mathrm{V}$ & $\mathrm{H}_{2}$ & $\mathrm{Ti}$ \\
\hline $\mathrm{wt} \%$ & $<0.08$ & $<0.25$ & $<0.25$ & $<0.2$ & $5.5-6.76$ & $3.5-4.5$ & 0.015 & Balance \\
\hline
\end{tabular}

Table 2 Processing parameters

\begin{tabular}{|c|c|c|c|c|c|}
\hline Sample & Clad layer & Laser power $(\mathrm{kW})$ & $\begin{array}{l}\text { Traverse speed } \\
\left(\mathrm{mm} \mathrm{min} \min ^{-1}\right)\end{array}$ & $\begin{array}{l}\text { Wire feed rate } \\
\left.(\mathrm{mm} \mathrm{min})^{-1}\right)\end{array}$ & $\begin{array}{l}\text { Powder feed rate } \\
\left(\mathrm{g} \min ^{-1}\right)\end{array}$ \\
\hline \multirow[t]{2}{*}{ Wall A } & 1-4th layer & 1.4 & 200 & 800 & - \\
\hline & 5th layer & 1.4 & 200 & 800 & 5 \\
\hline \multirow[t]{2}{*}{ Wall B } & 1-4th layer & 1.4 & 200 & 800 & - \\
\hline & 5th layer & 1.4 & 200 & 800 & 10 \\
\hline \multirow[t]{2}{*}{ Wall C } & 1-4th layer & 1.4 & 200 & 800 & - \\
\hline & 5th layer & 1.4 & 200 & 800 & 20 \\
\hline
\end{tabular}

depositions were performed inside a transparent enclosure (bag) filled with high purity argon gas supplied at $25 \mathrm{~L} \mathrm{~min}^{-1}$. This was done in order to prevent oxidation.

\subsubsection{Wall building}

First, walls comprising of five layers were built using a stepup height $(Z)$ of $1.0 \mathrm{~mm}$. The first four layers were single deposits of commercially pure (CP) Ti wire, and the uppermost layer was a concurrent deposit of Ni powder and Ti wire (see Fig. 2b). This was done because good interfacial bonding could not be formed between the substrate and the Ni-Ti deposited layer. Table 2 presents the processing parameters utilised for the wall building. These parameters were selected after series of trial experiments were undertaken in order to define a broad process window for the materials in question.

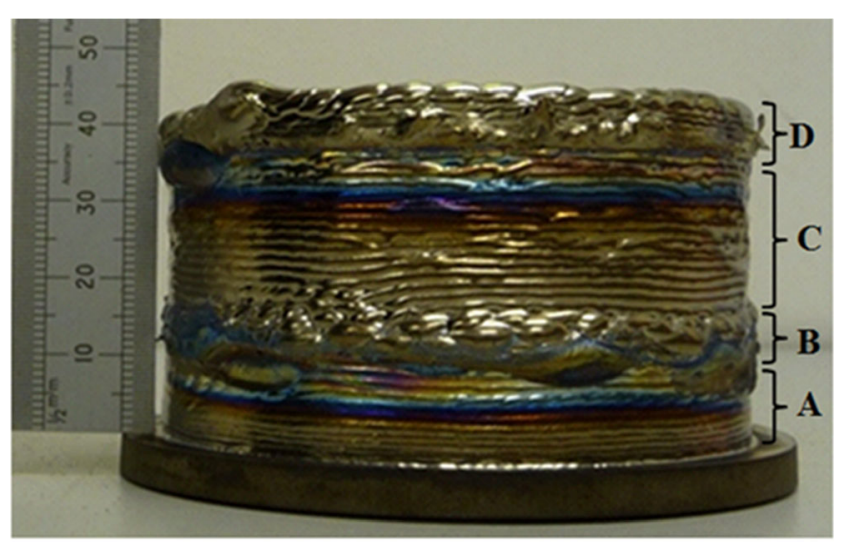

$A \& C=C P T i$ regions, $B \& D=N i-T i$ regions

Fig. 3 Functionally graded Ni-Ti cylinder built using DLMD by concurrent powder and wire feeding

\subsubsection{Functionally graded cylinder building}

In this case, a circular Ti-6Al-4V plate of diameter $80 \mathrm{~mm}$ and thickness $6 \mathrm{~mm}$ was used as the substrate. The circular plate was set to rotate at $327^{\circ} \mathrm{min}^{-1}$ (equivalent to traverse speed of $200 \mathrm{~mm} \mathrm{~min}{ }^{-1}$ ), while the laser head was fixed. The step-up height $(Z)$ was set at $1.0 \mathrm{~mm}$. Except for these changes, the setup for the deposition of a functionally graded cylinder was identical to that previously described in section 2.1. Throughout the deposition, Ni PFR was varied between 0 and $10 \mathrm{~g} \mathrm{~min}^{-1}$. This was done in order to demonstrate the capability of DLMD in building a functionally graded Ni-Ti structure. The cylinder building started with the feeding of only $\mathrm{CP}$ Ti wire at a feed rate of $800 \mathrm{~mm} \mathrm{~min}^{-1}$. The laser power was set at $1.4 \mathrm{~kW}$. After five layers of CP Ti wire have been successfully deposited, the laser power was reduced to $1.2 \mathrm{~kW}$. This was done so as to compensate for the heat accumulated in the previously built structure which could have caused excessive heating of the top layer if the laser power was maintained at $1.4 \mathrm{~kW}$. Excessive heating would have caused flattening of the layers thus making the preset stepup height $(Z)$ incorrect and deteriorate the process stability. The first ten layers (amounting to $\sim 10 \mathrm{~mm}$ cylinder height) of FG cylinder were built with CP Ti wire only.

At the beginning of the deposition of the 11th layer, $\mathrm{Ni}$ powder was fed concurrently with the $\mathrm{CP}$ Ti wire. The powder feed rate (PFR) was $10 \mathrm{~g} \mathrm{~min}^{-1}$, and wire feed rate (WFR) maintained at $800 \mathrm{~mm} \mathrm{~min}^{-1}$. The step-up height was increased to $1.2 \mathrm{~mm}$ so as to compensate for the increase in material deposition rate due to the powder injection. Five Ni-Ti layers were successfully deposited. Due to irregular powder feeding, undulating surface were observed at the top surface of the Ni-Ti layers. This was corrected by remelting the surface using $1.0-\mathrm{kW}$ laser power. A reasonably flat 
Fig. 4 Optical micrographs showing the cross-sections of laser-deposited walls comprising four clad layers of pure Ti wire and a Ni-Ti clad layer at the top. The Ni powder feed rates in the uppermost layers are a $5 \mathrm{~g} \mathrm{~min}^{-1}$, b $10 \mathrm{~g} \mathrm{~min}^{-1}$ and c $20 \mathrm{~g} \mathrm{~min}^{-1}$

Fig. 5 Backscattered electron SEM images of a a typical wall showing good fusion between $\mathbf{b}$ the top Ni-Ti clad layer and pure $\mathrm{Ti}$ wire clad layer and $\mathbf{c}$ the substrate and the pure Ti wire clad layer

Fig. 6 A picture showing the delamination of $\mathrm{Ni}$ - $\mathrm{Ti}$ clad layer from the Ti6Al4V substrate
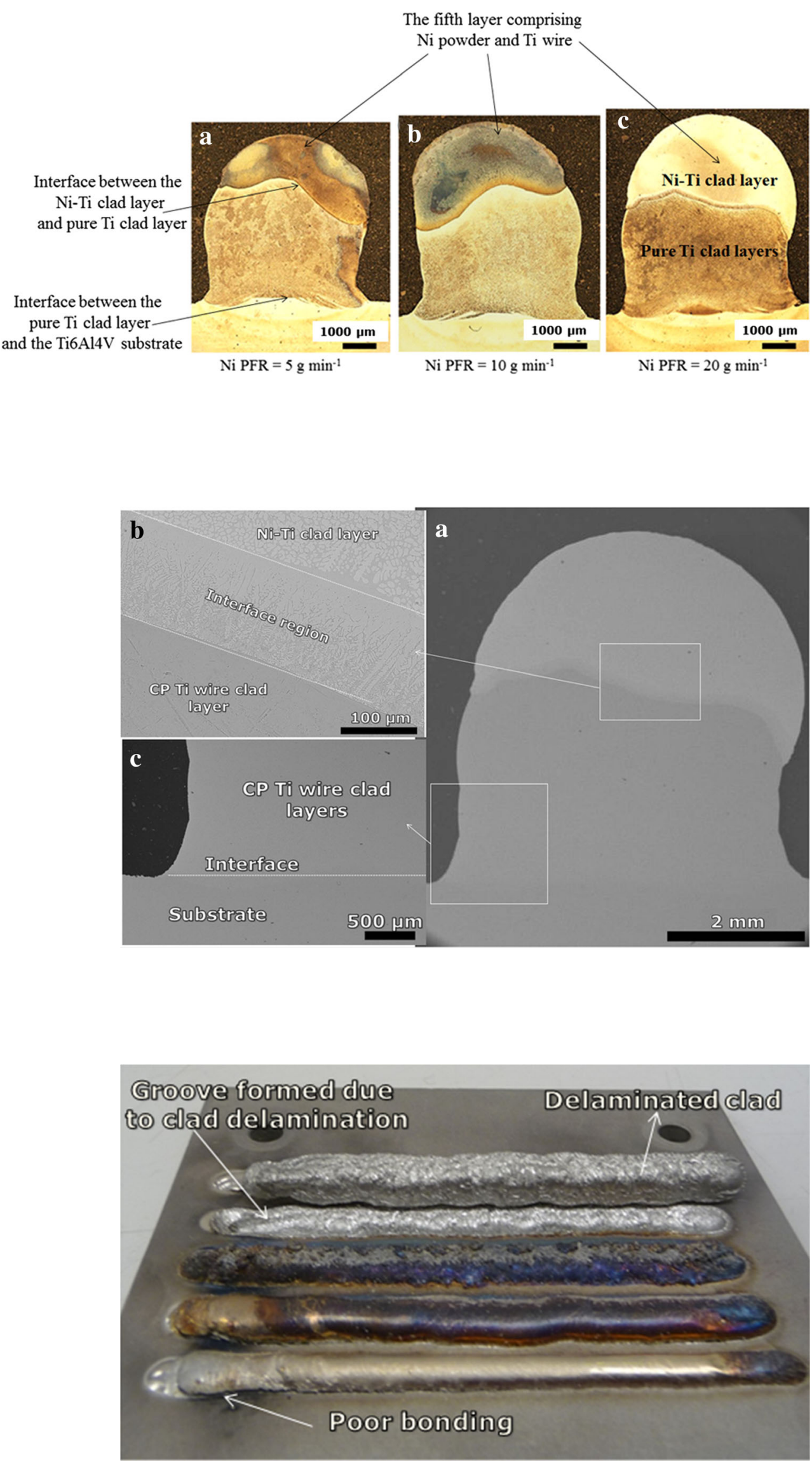
Fig. 7 a XRD spectra of the NiTi laser clad layers in the built walls. b A schematic diagram showing the location (at the uppermost layer) of XRD analysis a

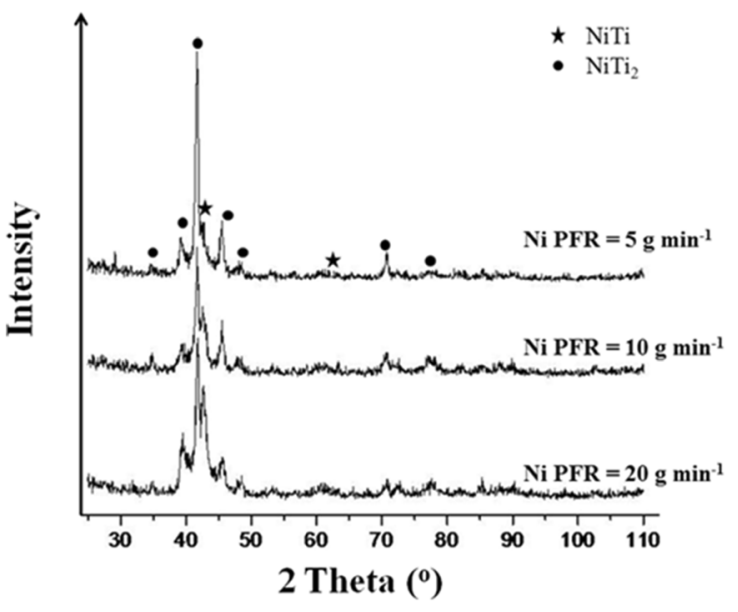

b

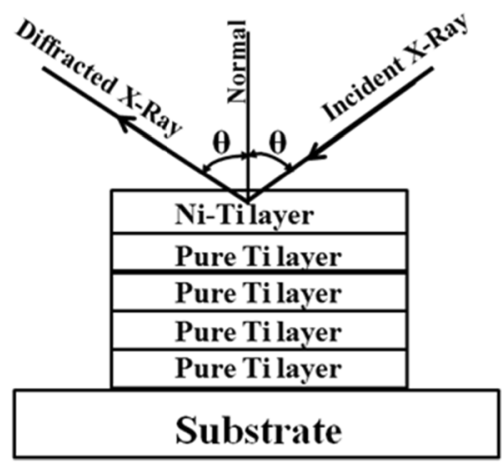

surface was achieved with this method. Thereafter, the deposition continued with the feeding of $\mathrm{CP} \mathrm{Ti}$ wire, and no $\mathrm{Ni}$ powder injection for a further 20 layers. The laser power was $1.2 \mathrm{~kW}$ and WFR maintained at $800 \mathrm{~mm} \mathrm{~min}^{-1}$.

Ni powder injection was reintroduced at the start of the 36th layer at a feed rate of $5 \mathrm{~g} \mathrm{~min}^{-1}$. All other parameters were constant. Five Ni-Ti layers were deposited using these parameters before the entire process was stopped. Figure 3 shows the picture of the built FG Ni-Ti cylinder before machining.

\subsection{Microstructural characterisation}

After laser processing, the microstructure of the deposited walls, including defect formation and metallurgical bonding between the (1) pure Ti and Ni-Ti laser clad layers and (2) pure Ti clad layer and the substrate, were investigated using optical and scanning electron microscopy (SEM). Phases present in the Ni-Ti (uppermost) layer were identified using X-ray diffractometry (XRD). The compositions of the phases present in

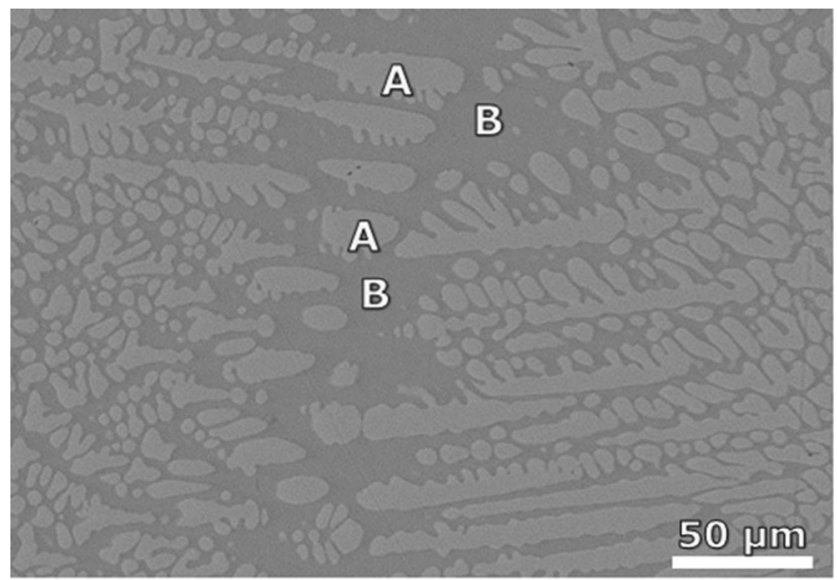

Fig. 8 Backscattered electron SEM image showing the microstructure of the Ni-Ti clad layer the Ni-Ti clad layer as a function of the Ni content were also determined using SEM in combination with energy dispersive spectroscopy (EDX). Also, EDX analysis (area scan of 50× $50 \mu \mathrm{m}$ ) was conducted at various regions within the Ni-Ti clad layers. This was undertaken in order to study the effect of changes in the Ni PFR on the compositions of the Ni-Ti layer. Another reason was to establish if the composition of the Ni$\mathrm{Ti}$ is consistent throughout the uppermost layer of each built wall. The area fraction of the phases present in the $\mathrm{Ni}$ - $\mathrm{Ti}$ clad layer as a function of the $\mathrm{Ni}$ content was determined. This was achieved by taking SEM micrographs ( $\times 500$ magnification) at 10 different locations within the transverse section of the top layer of the wall. The area fraction of the each of the phases present was determined from the SEM micrographs using the image processing software (Image J).

\subsection{Micro-hardness}

Micro-hardness testing was conducted on the polished crosssectional areas of the pure $\mathrm{Ti}$ and $\mathrm{Ni}$-Ti laser clad layers. The test was conducted along the centreline from the bottom to the top of the clad at a spacing of $0.2 \mathrm{~mm}$ between successive points. A Buehler Micromet 2100 series micro-hardness tester with a load of $300 \mathrm{gf}$ (i.e. $3 \mathrm{~N}$ applied for $15 \mathrm{~s}$ ) was used. The micro-hardness value of the substrate region near the clad layer was also determined using a similar method.

Table 3 Elemental composition of the phases labelled as A and B in Fig. 7

\begin{tabular}{|c|c|c|c|c|c|}
\hline \multirow[t]{2}{*}{ Symbol } & \multirow[t]{2}{*}{ Probable phase } & \multicolumn{2}{|c|}{ Weight (\%) } & \multicolumn{2}{|c|}{ Atomic (\%) } \\
\hline & & $\mathrm{Ti}$ & $\mathrm{Ni}$ & $\mathrm{Ti}$ & $\mathrm{Ni}$ \\
\hline A & NiTi & $46.4 \pm 0.1$ & $53.6 \pm 0.1$ & $51.5 \pm 0.2$ & $48.5 \pm 0.2$ \\
\hline B & $\mathrm{NiTi}_{2}$ & $63.1 \pm 0.3$ & $36.9 \pm 0.3$ & $67.7 \pm 0.3$ & $32.3 \pm 0.3$ \\
\hline
\end{tabular}


Table 4 Chemical composition of bottom, mid and top regions of the Ni-Ti layer in the FG walls

\begin{tabular}{|c|c|c|c|c|c|c|c|c|c|c|c|c|}
\hline & \multicolumn{4}{|c|}{$\mathrm{Ni}$-Ti composition at the interface/bottom region } & \multicolumn{4}{|c|}{$\mathrm{Ni}-\mathrm{Ti}$ composition at the mid region } & \multicolumn{4}{|c|}{ Ni-Ti composition at the top region } \\
\hline & \multicolumn{2}{|l|}{$w t \%$} & \multicolumn{2}{|l|}{ at. $\%$} & \multicolumn{2}{|l|}{$\mathrm{wt} \%$} & \multicolumn{2}{|l|}{ at. $\%$} & \multicolumn{2}{|l|}{ wt $\%$} & \multicolumn{2}{|l|}{ at. $\%$} \\
\hline & $\mathrm{Ti}$ & $\mathrm{Ni}$ & $\mathrm{Ti}$ & $\mathrm{Ni}$ & $\mathrm{Ti}$ & $\mathrm{Ni}$ & $\mathrm{Ti}$ & $\mathrm{Ni}$ & $\mathrm{Ti}$ & $\mathrm{Ni}$ & $\mathrm{Ti}$ & $\mathrm{Ni}$ \\
\hline Wall A & $70 \pm 0.2$ & $30 \pm 0.2$ & $74 \pm 0.2$ & $26 \pm 0.2$ & $65 \pm 2.6$ & $35 \pm 2.6$ & $69 \pm 1.8$ & $31 \pm 1.8$ & $66 \pm 2.8$ & $34 \pm 2.8$ & $69 \pm 2.2$ & $31 \pm 2.2$ \\
\hline Wall B & $69 \pm 0.4$ & $31 \pm 0.4$ & $72 \pm 0.4$ & $28 \pm 0.4$ & $59 \pm 1.4$ & $41 \pm 1.4$ & $63 \pm 1.1$ & $37 \pm 1.1$ & $60 \pm 0.9$ & $40 \pm 0.9$ & $64 \pm 1.1$ & $36 \pm 1.1$ \\
\hline Wall C & $68 \pm 0.3$ & $32 \pm 0.3$ & $72 \pm 0.4$ & $28 \pm 0.4$ & $51 \pm 0.6$ & $49 \pm 0.6$ & $56 \pm 0.6$ & $44 \pm 0.6$ & $52 \pm 0.5$ & $48 \pm 0.5$ & $55 \pm 0.6$ & $45 \pm 0.6$ \\
\hline
\end{tabular}

\section{Results and discussions}

\subsection{Metallurgical bonding}

Figure 4 presents the optical micrographs showing the crosssections of the three built walls. The cross-sections show no cracking or major pores. Each of the walls comprises five clad layers. The first four are clad layers of CP Ti wire, whereas the top layer is Ni-Ti clad. Figure 5 presents the backscattered electron SEM images showing strong interfacial bonding between (1) the substrate and the pure Ti wire clad layer and (2) between the top Ni-Ti clad layer and pure Ti wire clad layer. However, when the Ni powder and pure Ti wire were concurrently deposited on Ti-6Al-4V substrate, the Ni-Ti clad layer did not bond well with the substrate. In other words, delamination was observed at the clad-substrate interface, as shown in Fig. 6. Also, cracking was observed on the clad surface. These defects are probably due to the solidification of materials (molten) of dissimilar properties from a single-laser meltpool. The difference in the thermal expansion coefficient of the three materials is thought to be the cause of these defects.

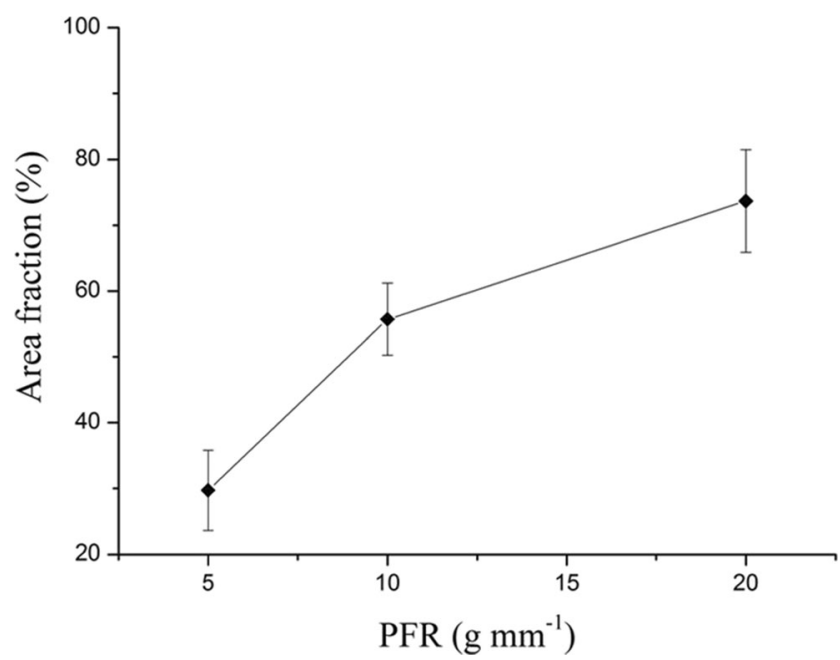

Fig. 9 A plot of the area fraction of the dendritic NiTi phase in the Ni-Ti laser clad layers as a function of the Ni powder feed rate

\subsection{Microstructural characterisation}

The XRD spectra of the topmost (Ni-Ti clad) layers of the three built walls are shown in Fig. 7. NiTi and $\mathrm{NiTi}_{2}$ phases were identified. NiTi peaks occurred mainly at $2 \theta=42$ and $62^{\circ}$. The $\mathrm{NiTi}_{2}$ phase fit to the peaks occurring at $2 \theta=35$, $39,41,46,50,71$ and $78^{\circ}$. The intensity of the NiTi phase increased as the Ni PFR increased.

The backscattered electron SEM micrograph showing the microstructure of the Ni-Ti laser clad layer reveals two distinct phases, as shown in Fig. 8. A light contrast dendritic precipitate marked as ' $\mathrm{A}$ ' is formed randomly on the dark grey matrix marked ' $\mathrm{B}$ '. The results of EDX analysis, which are averages of five measurements, conducted on the light contrast dendritic precipitates and dark grey matrix are presented in Table 3. The compositions of $\mathrm{Ni}$ and $\mathrm{Ti}$ in at. $\%$ are nearly equivalent in the phase marked ' $A$ '. Therefore, it is identified as NiTi phase. However, the $\mathrm{Ti} / \mathrm{Ni}$ atomic ratio in the dark grey matrix marked ' $\mathrm{B}$ ' is $2: 1$. Consequently, it is confirmed to be $\mathrm{NiTi}_{2}$.

EDX area scan $(50 \times 50 \mu \mathrm{m})$ was conducted at the interface between the $\mathrm{CP} \mathrm{Ti}$ (4th) layer and the Ni-Ti (5th) layer. Also, similar work was repeated within the mid region and top region of the Ni-Ti (5th) clad layer. The results, which are averages of five scans within each region, are presented for each of the three built walls in Table 4 . The results show the Ti composition is significantly higher at the interface between the $\mathrm{CP}$ $\mathrm{Ti}$ (4th) layer and the Ni-Ti (5th) layer. This is possibly due dilution caused by the remelting of the $\mathrm{CP} \mathrm{Ti}$ (4th) layer during the deposition of the Ni-Ti clad layer. Also, composition of the Ni-Ti clad layer is somehow consistent at the mid and top regions. Considering the results presented for the $\mathrm{Ni}-\mathrm{Ti}$ clad layers built with different Ni PFR, the Ni composition, at all positions, increased as the Ni PFR increased. However, the composition of the $\mathrm{Ni}$-Ti layer in wall $\mathrm{C}$ with the powder feed rate of $20 \mathrm{~g} \mathrm{~min}^{-1}$ and WFR of $800 \mathrm{~mm} \mathrm{~min}^{-1}$ is the closest to a ratio of $1: 1$ where the shape memory effect may be achieved.

In order to determine the effect of increasing $\mathrm{Ni}$ content on the clad microstructure, the area fraction (\%) of the dendritic phase 'A' identified as NiTi phase in each of the Ni-Ti clad layer was estimated. This, as presented in Fig. 9, is shown to increase with increasing the PFR (i.e. the amount of $\mathrm{Ni}$ 
Fig. 10 Backscattered electron SEM images revealing the centre of the Ni-Ti laser clad layers formed at varying Ni powder feed rate $\mathbf{a} 20 \mathrm{~g} \mathrm{~min}^{-1}$ and $\mathbf{b} 5 \mathrm{~g} \mathrm{~min}^{-1}$

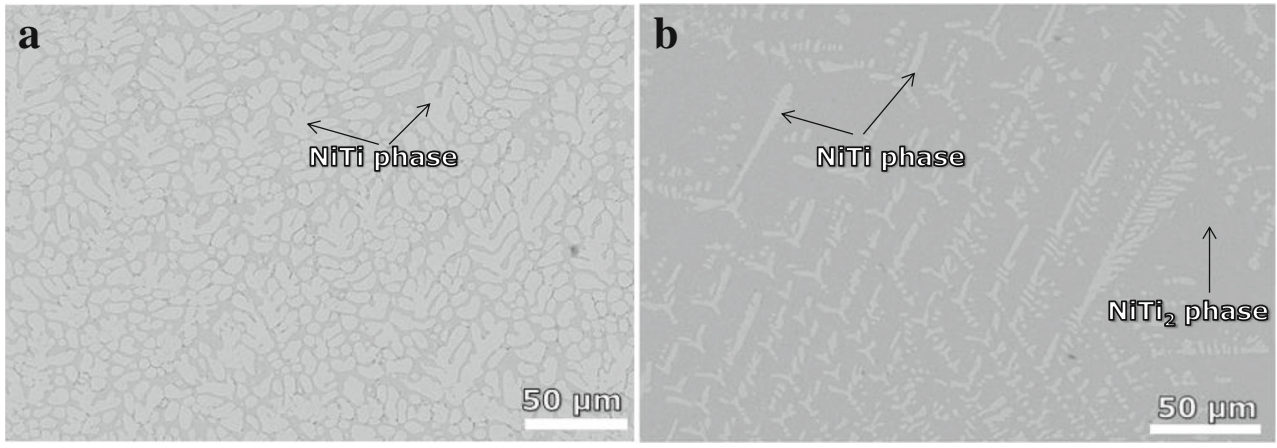

powder deposited into the laser meltpool). Backscattered electron SEM micrographs showing the centre of the Ni-Ti laser clad layers deposited at varying Ni PFR is shown in Fig. 10. At $20 \mathrm{~g} \mathrm{~min}^{-1}$, the NiTi phase appears to be bigger and higher in number density, whereas it is apparently thinner and lower in quantity in the Ni-Ti clad layer formed at $5 \mathrm{~g} \mathrm{~min}^{-1}$. This simply implies that the formation of the NiTi phase is promoted by increasing the $\mathrm{Ni}$ content.

\subsection{Micro-hardness}

Micro-hardness measurement along the centreline of the each of the deposited walls is presented in Fig. 11. The microhardness value of the substrate region close to the clad layer was also presented. The average hardness of the Ti-6Al-4V substrate after laser cladding ranged between 355 and $364 \mathrm{HV}_{0.3}$. This is close to the hardness of wrought Ti6Al4V plate $\left(350 \mathrm{HV}_{0.3}\right)$ as found in the literature [11]. The hardness of the pure $\mathrm{Ti}$ layer in the three walls shows no significant change. It ranged between 201 and $214 \mathrm{HV}_{0.3}$. Within the NiTi laser clad layers, there was significant difference in the micro-hardness measurements as the Ni powder feed rate varied. Values of $513 \pm 17 \mathrm{HV}_{0.3}, 435 \pm 15 \mathrm{HV}_{0.3}$ and $362 \pm$ $17 \mathrm{HV}_{0.3}$ were found at $5 \mathrm{~g} \mathrm{~min}^{-1}, 10 \mathrm{~g} \mathrm{~min}^{-1}$ and $20 \mathrm{~g} \mathrm{~min}^{-1}$, respectively. This is in agreement with the finding of $\mathrm{Ng}$ et al. [8] during the characterisation and corrosion study of $\mathrm{Ni}$-Ti laser surface alloyed with $\mathrm{Nb}$ or $\mathrm{Co}$. The mechanical properties of the built wall are believed to be influenced by the difference in the hardness as the $\mathrm{Ni}$ content changes.

The decrease in the micro-hardness of the Ni-Ti clad layer with increasing Ni PFR can be attributed to increased formation of NiTi phase as the Ni content increased. This shows that $\mathrm{NiTi}_{2}$ phase is a harder phase and reducing its area fraction in the clad microstructure lowers the micro-hardness of the Ni-Ti clad layer. This is confirmed by the higher micro-hardness values found at the interface between the $\mathrm{CP} \mathrm{Ti}$ and $\mathrm{Ni}-\mathrm{Ti}$ laser clad layers, as shown in the micro-hardness profile shown in Fig. 11. Previously, it was mentioned in section 3.2 that Ti composition is extremely high at the interface between the CP Ti clad layers and Ni-Ti clad layers indicating more formation of harder $\left(\mathrm{NiTi}_{2}\right)$ phase at the interface. This is most likely the cause for the increase in the micro-hardness value at
Fig. 11 Micro-hardness profile along the cross-sectional area of the built walls

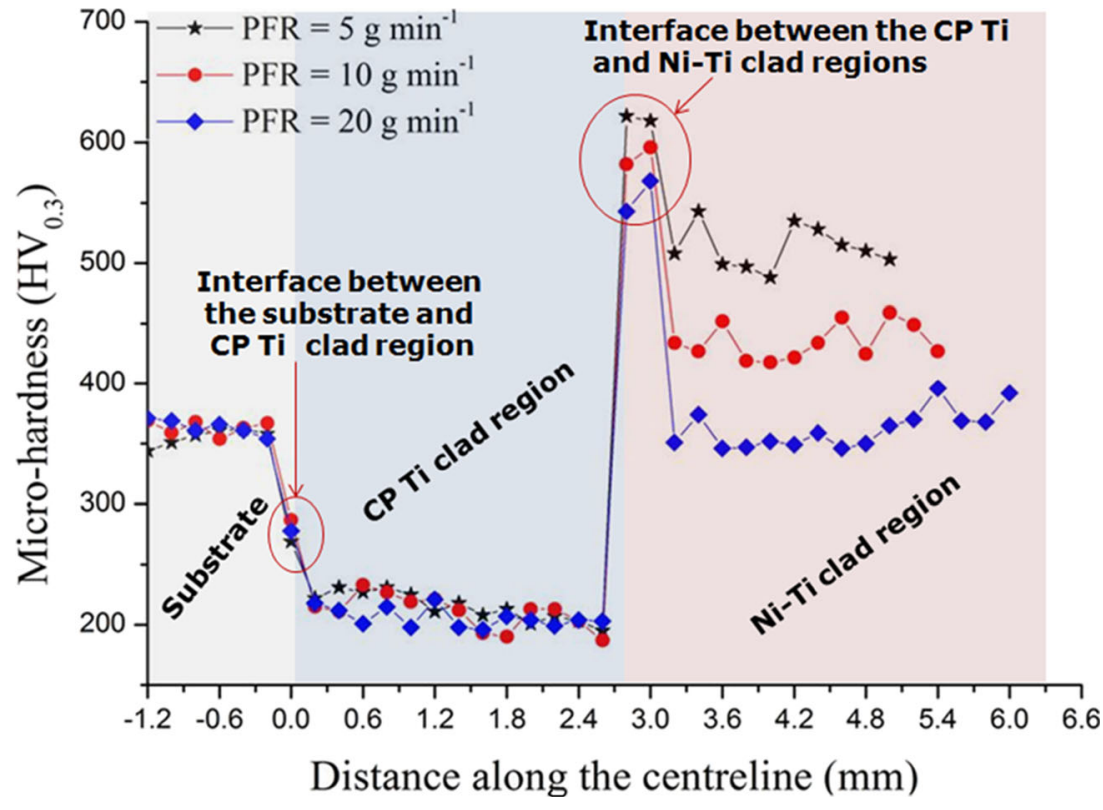




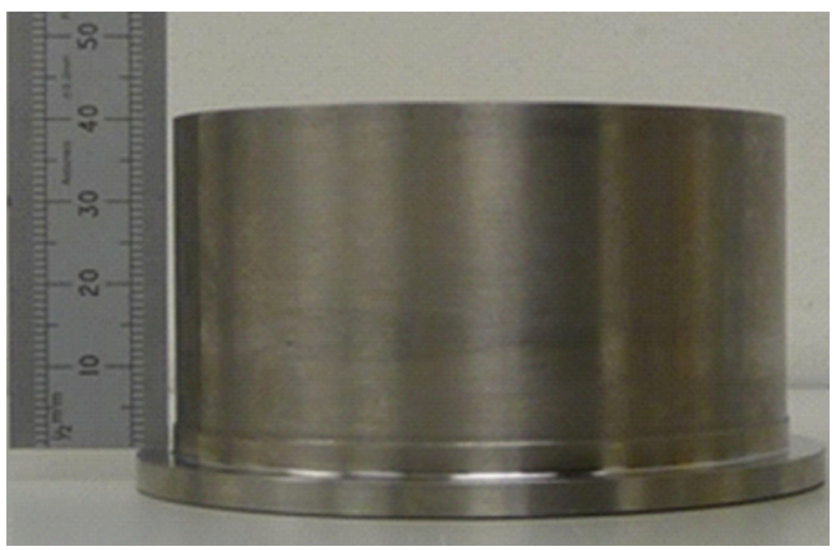

Fig. 12 Pictures of a functionally graded Ni-Ti cylinder after machining

this interface. Generally, the Ni-Ti laser clad layer demonstrates higher micro-hardness than the pure Ti clad layer because of the formation of hard matrix ( $\mathrm{NiTi}_{2}$ phase).

\subsection{Component building}

Figure 12 shows a 40-mm-high functionally graded Ni-Ti cylinder produced by concurrent feeding of Ni powder and $\mathrm{CP} \mathrm{Ti}$ wire using DLMD. The cylinder has internal and external diameters of $66 \pm 1$ and $74 \pm 1 \mathrm{~mm}$, respectively. The Ni and Ti compositions varied along the cylinder height indicating variations in the cylinder properties at different stages of the cylinder. As shown in Fig. 12, the built cylinder, after post machining (i.e. grinding), shows no pores and cracking. Also, it appears that the Ni-Ti regions bond strongly with the pure $\mathrm{Ti}$ regions without any visible defects. The development of this cylinder has shown that functionally graded Ni-Ti structures can be incorporated into design of parts by direct laser metal deposition. This makes the component fabrication flexible with the elimination of part joining processes.

\section{Conclusions}

This study demonstrates that it is possible to fabricate near net shape functionally graded structures with varying compositions by direct laser metal deposition using pure Ti wire and Ni powder as the feedstock materials. Strong interfacial bonding is achieved between the (1) pure Ti laser clad and Ti-6Al$4 \mathrm{~V}$ substrate and (2) laser clad layers of $\mathrm{Ni}-\mathrm{Ti}$ and pure $\mathrm{Ti}$ wire. The microstructure of the Ni-Ti clad layers comprised intermetallic phases which are $\mathrm{NiTi}_{2}$ matrix and dendritic NiTi precipitates. The formation of NiTi precipitates increases with increasing Ni content. The micro-hardness of the Ni-Ti clad layers is found to decrease with increasing Ni content giving a maximum of $513 \mathrm{HV}_{0.3}$ in this study. A very high microhardness (maximum of $620 \mathrm{HV}_{0.3}$ ) is found at the interface between the pure $\mathrm{Ti}$ and Ni-Ti laser clad layers suggesting
$\mathrm{NiTi}_{2}$ phase as a harder phase. Due to the formation of the intermetallic phases, the micro-hardness of Ni-Ti clad layers are found to be harder than the substrate (364 HV) and much harder than the pure Ti laser clad layers (214 HV).

Acknowledgments The authors would like to acknowledge the expertise and technical input from Mr. Stuart Branston. Also, the assistance rendered by Ericka Silme (MSc student) in the lab is appreciated.

Open Access This article is distributed under the terms of the Creative Commons Attribution License which permits any use, distribution, and reproduction in any medium, provided the original author(s) and the source are credited.

\section{References}

1. Elahinia MH, Hashemi M, Tabesh M, Bhaduri SB (2012) Manufacturing and processing of NiTi implants: a review. Prog Mater Sci 57:911-946

2. Man HC, Zhang S, Cheng FT, Guoc X (2005) Laser fabrication of porous surface layer on NiTi shape memory alloy. Mater Sci Eng A 404:173-178

3. Yan XJ, Gugel H, Huth S, Theisen W (2011) Microstructures and properties of laser cladding NiTi alloy with $\mathrm{W}$ for biomedical applications. Mater Lett 65:2934-2936

4. Dayananda GN, Varughese B, Harish Kumar T, Subba Rao M (2005) Development of an SMA based smart landing gear for rotorcraft and other similar applications, in Proceedings of Fourth International Conference on Smart Materials, Structures and Systems. Bangalore, India. $\mathrm{p} \mathrm{SB}-36$ to 44

5. Clare AT, Paul RC, Davies S, Sutcliffe JC, Tsopanos S (2008) Selective laser melting of high aspect ratio 3D nickel-titanium structures two way trained for MEMS applications. Int J Mech Mater Des 4(2):181-187

6. Fadlallah SA, El-Bagoury N, Gad El-Rab SMF, Ahmed RA, ElOusamii G (2014) An overview of NiTi shape memory alloy: corrosion resistance and antibacterial inhibition for dental application. $\mathrm{J}$ Alloys Compd 583:455-464

7. Kosec T, Mocnik P, Legat A (2014) The tribocorrosion behaviour of NiTi alloy. Appl Surf Sci 288:727-735

8. Ng KW, Man HC, Yue TM (2011) Characterization and corrosion study of NiTi laser surface alloyed with $\mathrm{Nb}$ or Co. Appl Surf Sci 257(8):3269-3274

9. Abioye TE, Folkes J, Clare AT (2013) A parametric study of Inconel 625 wire laser deposition. J Mater Process Technol 213(12):21452151

10. Azo Materials. Titanium alloys - Ti-6Al-4V Grade 5. 2002. Available at www.azom.com/article.aspx?articleID $=1547$. Accessed on 15 th Dec., 2014.

11. Farayibi PK, Folkes JA, Clare AT (2013) Laser deposition of Ti-6Al$4 \mathrm{~V}$ wire with WC for functionally graded components. J Mater Manuf Process 28(1-5):514-518

\section{Further work}

The future work includes the demonstration of the shape memory effect of a section of the cylinder. The micro-hardness and corrosion study at different stages of the cylinder will also be done. 